\title{
Creating a Realistic Weather Environment for Motion-Based Piloted Flight Simulation
}

\author{
Taumi S. Daniels, Philip R. Schaffner, Emory T. Evans, Robert T. Neece, and Steven D. Young \\ "NASA Langley Research Center, Hampton, VA, 23681, USA
}

\begin{abstract}
A flight simulation environment is being enhanced to facilitate experiments that evaluate research prototypes of advanced onboard weather radar, hazard / integrity monitoring (HIM), and integrated alerting and notification (IAN) concepts in adverse weather conditions. The simulation environment uses weather data based on real weather events to support operational scenarios in a terminal area.

A simulated atmospheric environment was realized by using numerical weather data sets. These were produced from the High-Resolution Rapid Refresh (HRRR) model hosted and run by the National Oceanic and Atmospheric Administration (NOAA). To align with the planned flight simulation experiment requirements, several HRRR data sets were acquired courtesy of NOAA. These data sets coincided with severe weather events at the Memphis International Airport (MEM) in Memphis, TN. In addition, representative flight tracks for approaches and departures at MEM were generated and used to develop and test simulations of (1) what onboard sensors such as the weather radar would observe; (2) what datalinks of weather information would provide; and (3) what atmospheric conditions the aircraft would experience (e.g. turbulence, winds, and icing).

The simulation includes a weather radar display that provides weather and turbulence modes, derived from the modeled weather along the flight track. The radar capabilities and the pilots controls simulate current-generation commercial weather radar systems. Appropriate data-linked weather advisories (e.g., SIGMET) were derived from the HRRR weather models and provided to the pilot consistent with NextGen concepts of use for Aeronautical Information Service (AIS) and Meteorological (MET) data link products.

The net result of this simulation development was the creation of an environment that supports investigations of new flight deck information systems, methods for incorporation of better weather information, and pilot interface and operational improvements for better aviation safety. This research is part of a larger effort at NASA to study the impact of the growing complexity of operations, information, and systems on crew decision-making and response effectiveness; and then to recommend methods for improving future designs.
\end{abstract}

\footnotetext{
* Research Scientists, Vehicle Systems Safety Technologies Project, Aviation Safety Program
}

\section{Introduction}

In the development of advanced flight deck systems to support safe and efficient operations in the presence of potentially hazardous weather conditions in the Next Generation Air Transportation System (NextGen), piloted simulation experiments in a motion-base simulator are being used to evaluate research prototypes of hazard sensors, information processing systems, and display concepts. This research is being conducted in the NASA Langley Research Flight Deck (RFD) Simulator, an advanced all-glass jet transport-class flight simulator.

In prior research, [1], [2], and [3] described testing the Weather Information Management System (WIMS), as part of the FLYSAFE (www.eu-Flysafe.org) architecture, for hazardous weather and terrain in a flight simulator. Weather data was generated by a mesoscale non-hydrostatic model for a $200 \mathrm{~km}$ square domain about Innsbruck, Austria, where the Alps mountain range represented the hazardous terrain. Their research included a weather model that used a nested grid with $10,2.5$ and $1 \mathrm{~km}$ resolutions. The model generated two weather scenarios, in-flight icing and severe convection, that were used in a full flight simulator Generic Research Aircraft Cockpit Environment (GRACE). The authors described integrating the in-flight simulated weather data with data from ground-based sources using the WIMS. Pilots were presented with METARs and SIGMETs based on the modeled weather data. Also, an airborne doppler weather radar database was driven by the modeled weather data. Pilots in the flight simulator were presented with data from this radar database. The authors did not test turbulence as a weather hazard.

Other researchers described a flight simulation with depictions of out-the-window scenery matching the weather. This system combined weather object geometry with a terrain database to create real-time visual out-the-window imagery for a flight deck simulator and was described by [4].

The research described here builds on the previous efforts. In order to provide a realistic weather environment for the RFD simulation experiments, numerical weather model data was employed to achieve three capabilities: (1) The weather models provide the weather conditions in which the simulator operates, including wind fields, turbulence, temperature, and precipitation, and resulting icing conditions. (2) The numerical weather models are used as the basis for real- 
time high fidelity simulations of weather hazard sensors, the initial efforts being to model state of the art airborne weather radar systems. (3) The numerical weather model data was used to create data linked weather information for use by on board information processing systems and displays, and these data are directly available to the flight crews.

The numerical weather data sets employed for the initial implementation were produced by the High-Resolution Rapid Refresh (HRRR) model as described by [5], [6], and [7]. The HRRR model is a storm-resolving model which assimilates a multitude of observations. Hourly forecasts of 3-D output fields include temperature, absolute humidity, winds, and rain/graupel/snow/ice concentrations. The data sets are on a $3-\mathrm{km}$ grid with 50 altitude levels from the ground to the top of the atmosphere. Several data sets for severe weather days at the Memphis airport (MEM), the site selected for the simulation experiments, were obtained by NASA courtesy of NOAA. Numerous sample flight tracks for approaches and departures at MEM were obtained and were used in the development of the weather environment simulation. These flight tracks are the basis for the air traffic environment for the piloted simulation experiments.

As pilots fly the simulation, the motion-based simulator provides a realistic experience driven by the model winds and turbulence estimated from 3-D wind variability. The simulator can also exhibit degraded performance due to icing conditions.

The weather radar simulation provides a radar display, including weather and weather plus turbulence modes, derived from the weather along the flight track. The radar capabilities and the pilot's controls simulate current-generation commercial weather radar, within the constraints imposed by the need to generate and display an ARINC 708 radar data stream in real time. NextGen data linked weather products will be available to the pilot. For this research, weather products will be available to the pilot as per [8] and [9].

This development of an aircraft weather environment is one component of a larger simulation system. This system includes Integrated Alerting and Notification (IAN) and Hazard and Integrity Monitoring (HIM), initially described in [10]. These two systems were both developed via a NASA cooperative research agreement with Ohio University. As described in [11], HIM determines what is hazardous to the aircraft and IAN displays this information to the pilot. The IAN/HIM required as input weather objects or regions of hazardous airspace. These weather objects are depicted as cylindrical regions and were generated from the HRRR radar reflectivity data.

Future enhancements of the simulation system may include rendering of out the window views of the weather, HRRR based ceiling and visibilility, and modeling of additional sensors, such as Lidar and forward-looking infrared
(FLIR) imaging systems. The resulting capabilities will enable evaluation of systems implementing NASA research concepts and weather products in a realistic environment.

\section{Flight Simulator}

A description of the RFD simulator was provided by [12], although the simulator system has been modified extensively since then. The RFD simulator employs a Boeing 757200 aircraft aerodynamic model. The cockpit includes four 17-inch LCDs on which primary flight information, navigation/map information, engine information, and other specified system parameters are displayed. As shown in Figure 1, these displays are similar in form and function to those used on the Boeing 787.

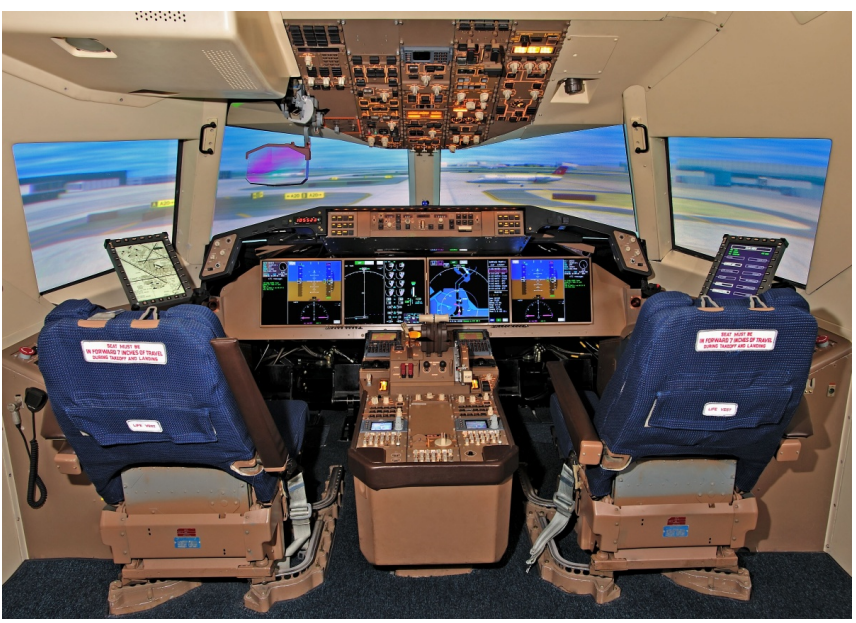

Figure 1: View of Research Flight Deck cabin.

Electronic Flight Bag (EFB) displays are installed on both the left and right side. There are also two control display units for pilot interaction with the FMS. There is a heads-up display mounted for use by the left-seat pilot, and there is a center aisle stand mounted between the two pilots.

Each pilot has a two-axes side stick control loader system for pitch/roll control and a set of control loaded rudder pedals. The cockpit's visual system is a panorama system, which provides 200 degrees horizontal field-of-view and 40 degrees vertical field-of-view of the external scene. The RFD is capable of operating in both a fixed-base and motion-based platform.

For the piloted research studies in the RFD simulator, the pilot and co-pilot have separately controlled radar displays in addition to their own EFBs. The motion base is driven based on 3-D winds and turbulence estimated from the HRRR numerical weather model. HRRR based in-flight icing effects will be simulated by degraded aircraft performance. 


\section{Weather Model}

For this research, a first step to develop the required simulation capability was to determine example significant weather events at MEM. Three were selected that resulted in reduced throughput of air traffic at MEM. These storms were typified by heavy rain and very strong winds, but not so severe that the airport was closed. Event data from [13] included a major storm on 12/5/2011, when a MEM ground delay program commenced at 11:00 PM lasting for two hours. On 4/26/2011, MEM had a delay starting at 10:45 PM, and finally on 2/24/2011, the delay started at 11:00 PM. For each of these three events, HRRR analysis data was acquired corresponding to the time just before the airport closure. Also, for the three events, forecast data (one hour after the analysis data) was acquired that corresponded to just after the program delay start time. Thus, weather motion could be interpolated between the two time samples.

HRRR data sets (both analysis and forecast) were processed using the following procedure. Each data set was converted from GRIB2 format to NetCDF format, the lowest 36 pressure levels (corresponding to altitudes from the surface to about FL450) were extracted, and the output constrained to those data points located within a $600 \mathrm{~km}$ by $600 \mathrm{~km}$ square centered on MEM. HRRR data has 42 total levels: 40 pressure levels from $25 \mathrm{hPa}$ to $1000 \mathrm{hPa}$ plus $1013 \mathrm{hPa}$ and one at the surface. The entire HRRR domain is illustrated in Figure 2.

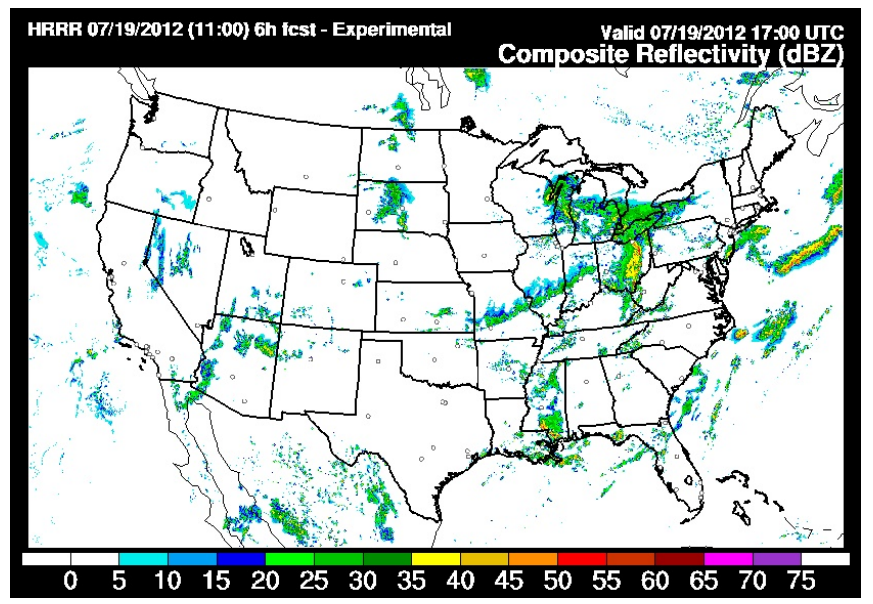

Figure 2: Illustration of entire HRRR domain

Within each data set, the following variables were extracted: longitudinal, lateral, and vertical wind velocities; temperature; absolute humidity; rain water mixing ratio; cloud ice content; graupel content; and geopotential height. From these variables, geometric height, vertical wind, and radar reflectivity and icing were estimated. Future enhancements include visibility and RFD windscreen imagery.

HRRR data is computed on a Lambert conformal conic grid with a $3-\mathrm{km}$ grid spacing over the entire CONUS. A correction to HRRR wind direction is made to achieve the true wind direction. The HRRR model north direction is only parallel to true north at the center of the Lambert conic projection, thus the wind components must be rotated based on their domain location.

The HRRR estimate of rain rate has two components. Rain drops fall to the ground as part of the grid-scale Thompson microphysics scheme as described by [14]. Also, HRRR modeled precipitation is derived from parameterized deep convection, as described by [15].

\section{Radar Reflectivity Estimation}

Radar reflectivity is given by [16] as

$$
Z=\frac{1}{\Delta V} \sum_{i} \pi^{5}\left|\frac{m^{2}-1}{m^{2}+2}\right| \frac{D_{i}^{6}}{\lambda^{4}}
$$

where $\Delta V$ is the radar resolution volume, $m$ is the complex index of refraction of water, $D_{i}$ is the diameter of the $i^{t h}$ rain drop, and $\lambda$ is the radar wavelength. Usually, only one radar type is considered at a time, so wavelength is considered a constant. A different parameter, reflectivity factor, is used to represent the reflectivity. This alternate parameter eliminates $\lambda$ from the equation above.

Prior research has shown that reflectivity $Z$ is related to rain rate $R$ by $Z=\alpha R^{\beta}$. The values for the two constants have been studied by other researchers including [17]. Their reflectivity estimates were based on Rayleigh scattering. The authors found very slight temperature dependence of radar reflectivity and rain fall rate. An analytical power law relation between radar reflectivity and rain fall rate based on the microphysics of rain drop size distribution was derived in [18]. In [19], an analysis of the cloud liquid water content and radar reflectivity relationship was given and they found that drop size is underestimated. They also noted an altitude dependence in the relationship that was not well understood.

In [20], exponential relations for estimating radar reflectivity from snow particle size distribution and from precipitation rate were reported. Values for $\alpha$ and $\beta$ from [21] for the equivalent radar reflectivity from measured snow size spectra were listed. A derivation of equivalent radar reflectivity from snow and ice particles and conversely, how to estimate snowfall from radar observations was provided by [22]. In [23], the authors simulated satellite based radar reflectivity from various ice crystal shapes. They found that radar backscatter from nonspherical shapes is required to accurately compute the vertical reflectivity. In particular, they found that Mie resonance effects from ice particles greater in size than $1 \mathrm{~mm}$ reduced the radar backscatter. Finally, [24] examined radar reflectivity versus snow fall rates and compared resulting $\alpha$ and $\beta$ parameters after varying snow mass size distributions, fall velocities, and particle size distributions. 
For our research, an alternate approach for real time estimation of radar reflectivity was used. Rain, snow, and graupel rates from the HRRR numerical weather model gridded output can be used to estimate radar reflectivity assuming Rayleigh scattering. This assumption is valid for both $\mathrm{S}$ band and $\mathrm{X}$ band radar wavelengths, according to [17].

As noted by [25], a radar reflectivity algorithm was given as a summation of contributions from rain, snow, and graupel. Each reflectivity component allows for explicit hydrometeor number densities by particle diameter. In particular, densities are assumed for: rain drops as $\rho_{l}=1000 \mathrm{~kg} / \mathrm{m}^{3}$, snow particles as $\rho_{s}=100 \mathrm{~kg} / \mathrm{m}^{3}$, and graupel particles as $\rho_{g}=400 \mathrm{~kg} / \mathrm{m}^{3}$. Each type has exponential size distribution given as

$$
N(D)=N_{0} e^{-\phi_{r} D}
$$

where $N_{0}=8 \times 10^{6}, 2 \times 10^{7}$, and $4 \times 10^{6} \mathrm{~m}^{-4}$ for rain, snow, and graupel, respectively. Also, $\phi_{r}$ is defined as a rain slope parameter from

$$
\phi_{r}=\left(\frac{\pi N_{0} \rho_{l}}{\rho_{a} q_{r}}\right)^{1 / 4}
$$

where $q_{r}$ is the HRRR rain water mixing ratio and $\rho_{a}$ is the density of dry air.

Assuming all rain drops are spherical with a number density given by Equation 2, integrating Equation 1 yields the reflectivity (in units $\mathrm{mm}^{6} \mathrm{~m}^{-3}$ ) as

$$
Z_{r}=\Gamma(7) N_{0} \phi_{r}^{-7}
$$

where the Gamma function is equivalent to the sixth moment of the size distribution for rain and $\Gamma(7)=720$.

For snow particles, the reflectivity is

$$
Z_{s}=\chi \Gamma(7) N_{0} \phi_{s}^{-7}\left(\frac{\rho_{s}}{\rho_{l}}\right)^{2}
$$

where $\chi=0.224$, a constant due to ratios of dielectric factors for liquid water and ice and ratios of densities of water and ice. The snow slope factor is given as

$$
\phi_{s}=\left(\frac{\pi N_{0} \rho_{s}}{\rho_{a} q_{s}}\right)^{1 / 4}
$$

where $q_{s}$ is the HRRR snow mixing ratio.

The equations for reflectivity due to graupel are the same as Equation 5 and Equation 6 with the substitution of $\rho_{g}$ for $\rho_{s}, q_{g}$ for $q_{s}$, and also using $N_{0}$ for graupel in Equation 6

Thus, [25] estimated the radar reflectivity (in units dBZ) as the sum of the reflectivities for rain, snow and graupel

$$
Z=10 \log _{10}\left(Z_{r}+Z_{s}+Z_{g}\right)
$$

This formulation from [25] only accounts for Rayleigh scattering, though the author noted that Mie scattering effects due to large graupel only account for slight $\mathrm{dBZ}$ changes. In order to achieve real time performance, the antenna pattern and the usual integration over the main beam and significant side lobes is ignored. The antenna is represented by a "boxcar" pattern representing the $3^{\circ}$ nominal beamwidth.

In Figure 3, a sample plot of radar reflectivity is shown for altitude $5580 \mathrm{ft}$. In the plot, the MEM domain is illustrated, and MEM is located at approximately $35^{\circ} \mathrm{N}, 270^{\circ} \mathrm{W}$.

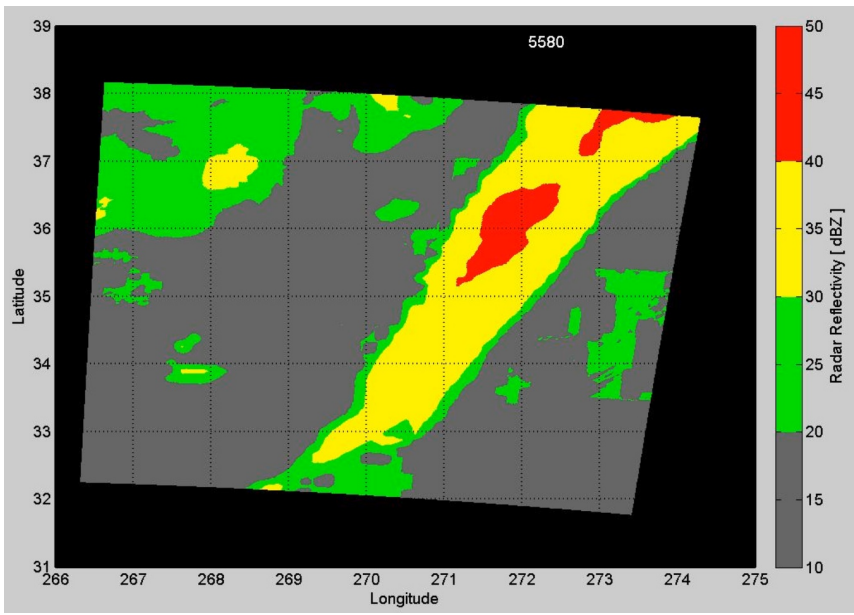

Figure 3: Sample of Estimated Radar Reflectivity

\section{Ground-Based Vs. Airborne Radar}

Next generation radar (NEXRAD) is a National Weather Service network of ground-based S-band Doppler weather radars and is described in [26]. Most commercial transport aircraft are equipped with an X-band Doppler weather radar. Both of these radar systems were simulated from the same HRRR gridded data.

In prior research, [27] described a system for combining on-board weather radar data with uplinked NEXRAD data onto a single display. The authors addressed some of the issues associated with using NEXRAD imagery in the cockpit. Aside from these human factors considerations, some technical challenges were also addressed. In particular, the authors gave ranges for NEXRAD dBZ levels to coincide with the on-board weather radar reflectivity color scale.

For this research, NEXRAD and on-board radar are not displayed together, rather the two different radar reflectivity values were computed from the same HRRR data. X-band airborne radar has a wavelength $\lambda=3 \mathrm{~cm}$ while $\mathrm{S}$-band NEXRAD is $10 \mathrm{~cm}$. The wavelength dependence in Equation 1 is one of several differences that affect reflectivity estimates. Others include path length attenuation and complex index of refraction dependence on wavelength. Other radar system differences include hardware parameters such as antenna size and gain and radar transmitter power. Also, for larger hydrometeors (large graupel), Mie scattering becomes an issue. For 
the purposes of this research, all of these radar differences were deemed to cause sufficiently small reflectivity differences from those estimates given by Equation 7

The overall MEM domain was appropriately subdivided using each cell size, and the resulting spatial locations were used to interpolate reflectivity values (in 3-D) for the two different displays. In particular, the NEXRAD resolution cell (super resolution mode) is $0.5^{\circ}$ by $0.25 \mathrm{~km}$ out to $300 \mathrm{~km}$. Using the Millington, TN NEXRAD radar site $\left(35.34569^{\circ} \mathrm{N}\right.$, $271.126507^{\circ} \mathrm{W}$ ), and an elevation angle of $0.5^{\circ}$, a base reflectivity map was created by interpolating the HRRR derived reflectivity given by Equation 7. A sample base reflectivity image is shown in Figure 4 overlayed on a sectional chart with aircraft position and heading depicted as a white triangle near the bottom center of the figure. This type of image is intended to be displayed on the EFB, but without aircraft position indicated.

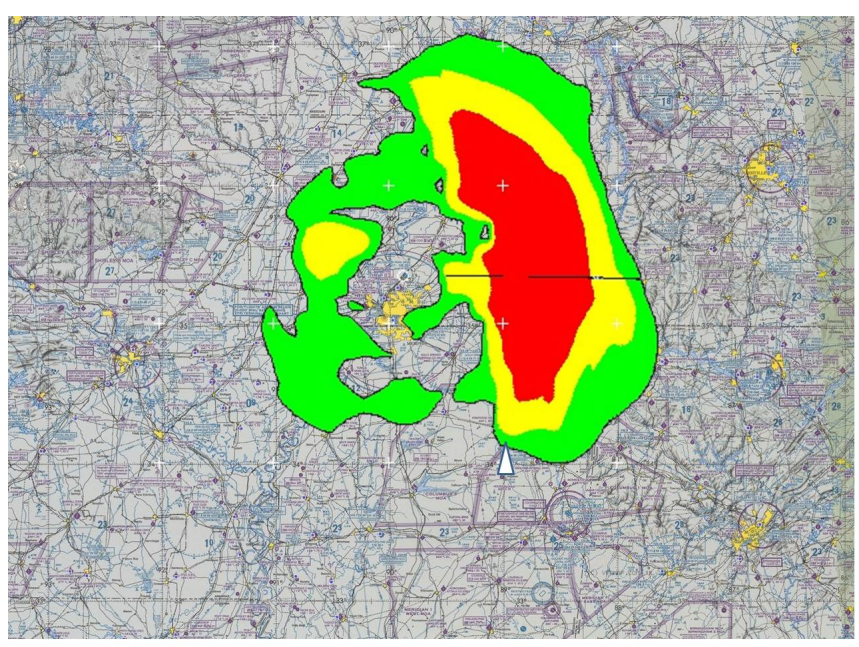

Figure 4: Sample of NEXRAD Radar Reflectivity

By a similar procedure, airborne weather radar is a 3-D interpolation of the HRRR derived reflectivity. The locations for a semi-circular set of points, representing the sweep of the radar, are computed based upon the aircraft location and heading. The airborne radar operation assumes aircraft tilt, roll, and yaw corrections maintain the aircraft at zero angle of attack, in level flight perpendicular to the vertical. In addition, the pilot-commanded radar range setting is used to determine the radius of the semi-circle. The commanded radar elevation angle is used to determine the angle of the plane of the semicircular radar scan relative to a plane perpendicular to the vertical. At each of the semi-circular set of points, radar reflectivity is interpolated within the larger 3-D HRRR grid of reflectivity.

This interpolation is performed at a rate of about $1 \mathrm{~Hz}$ to meet the ARINC-708 radar display rate of $0.25 \mathrm{~Hz}$. A sample airborne weather radar plot is shown in Figure 5, and is typical of what would be displayed in the flight deck simulator. Within the RFD, the intent is to display the radar reflectivity on either the pilot or co-pilot PFDs, NDs or (optionally on) the EFBs. The plot is from reflectivity data at the same altitude as the plot of Figure 3

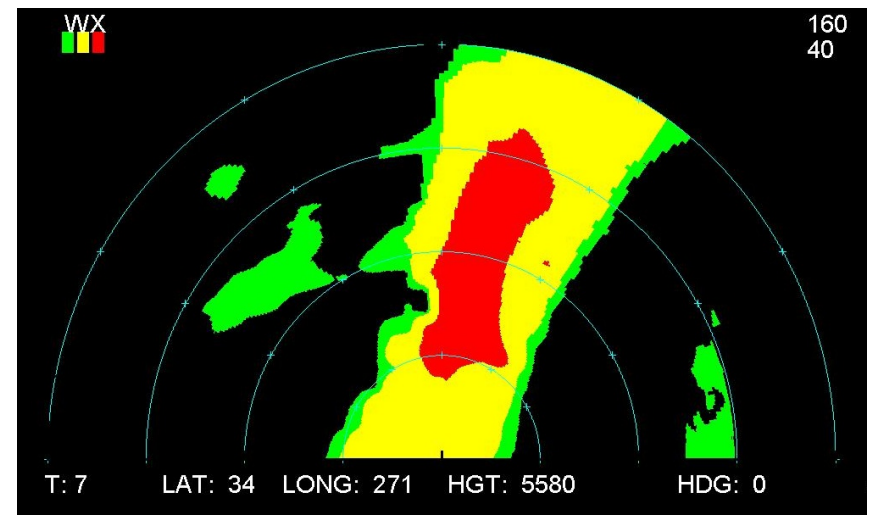

Figure 5: Sample of Airborne Weather Radar Reflectivity

\section{Winds Aloft}

The HRRR model output includes the two horizontal wind components, $U$ (North-South) and $V$ (East-West). Each of these 3-D gridded products were corrected to account for their Lambert Conformal Conic projection. This projection has a center longitude of $97.5^{\circ}$ West. Thus, the winds were rotated from model coordinates to the true directions.

For the vertical wind component, the HRRR model output is the vertical velocity (pressure), $W_{p}$, with units of $\mathrm{Pa} / \mathrm{s}$. This parameter field was converted to vertical wind with units of $\mathrm{m} / \mathrm{s}$ by a version of the hydrostatic equation at altitude $z$, given by

$$
W(z)=\frac{-W_{p}(z) R_{s} T(z)}{P(z) g(z)}
$$

where dry air specific gas constant $R_{s}=287.04 \mathrm{~J} / \mathrm{kg} \mathrm{K}, T$ is temperature, $P$ is pressure, and $g$ is gravity.

\section{Turbulence Estimation}

The RFD motion base is configured to follow a Boeing 757-200 aircraft aerodynamic model. Using wind and turbulence inputs, this model computes the aircraft response to drive the motion base for the RFD cabin. The HRRR 3$\mathrm{D}$ winds are input to the aerodynamic model and, at a low update frequency, used to compute a turbulence parameter $T_{p}$ (0 none, 2 to 3 light, 4 moderate, 6 severe, 21 - extreme).

The HRRR grid point spacing of $3 \mathrm{~km}$ is equivalent to about $25 \mathrm{~s}$ traversal time for an aircraft on approach. Thus, this spacing results in an update frequency too low for the RFD. For this research, a statistical approach was used. The HRRR 3-D winds were used to estimate the amplitude range 
for 3-D turbulence. A statistical model was used to generate this 3-D turbulence.

In order to derive the amplitude, a per unit mass turbulent kinetic energy (TKE) is computed in [28] as

$$
T K E=\frac{1}{2}\left[U^{\prime 2}+V^{\prime 2}+W^{\prime 2}\right]
$$

where the primes indicate gust values, or wind velocities with the mean removed $\left(U^{\prime}=U-\bar{U}\right)$. A sample TKE field at altitude $5580 \mathrm{ft}$ is illustrated in Figure 6 Usually, the wind velocities are averaged over some time interval. This time-based statistical approach is not used for this research as there are only two data sets per weather event, or simply two available time samples.

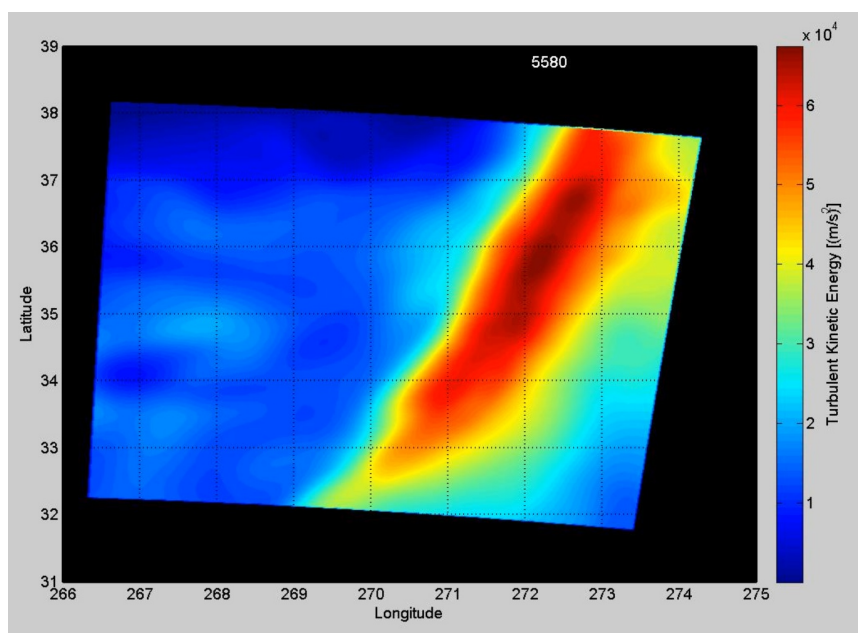

Figure 6: Sample of Turbulent Kinetic Energy

In [29], the authors describe a technique to simulate atmospheric turbulence. A similar approach is employed for the RFD B757 simulator model, which has a library of statistical turbulence models that can drive the motion base. These include:

Dryden First Order Model - Gaussian noise passed through first order filters generates longitudinal, lateral, and vertical turbulence.

Dryden Second Order Spectra Turbulence Model - Gaussian noise passed through second order filters.

Gaussian Model - Generates random noise with a Gaussian distribution without filtering.

The turbulence model to be used was chosen based on preliminary experiments using the motion base simulator prior to the commencement of the piloted simulations.

The turbulence parameter, $T_{p}$, is used to scale the random values from the chosen distribution and produce velocity values to be added to the low frequency 3-D winds from HRRR. This parameter is computed from the linear relation

$$
T_{p}=\gamma_{1} T K E+\gamma_{2}
$$

where scale factor $\gamma_{1}$ and amplitude adjustment $\gamma_{2}$ are determined empirically to produce the desired RFD ride quality.

The aerodynamic model also has a turbulence transition height of $2500 \mathrm{ft}$ AGL. When the aircraft model descends below the transition altitude, the turbulence motion will start to fade out until reaching $50 \mathrm{ft}$. The aerodynamic model will not produce turbulence below $50 \mathrm{ft}$.

\section{Icing Estimation}

In very general terms, the conditions for the formation of supercooled liquid water (SLW) include a temperature range between $0^{\circ} \mathrm{C}$ and $-20^{\circ} \mathrm{C}$, a liquid water content less than $0.25 \mathrm{~g} / \mathrm{m}^{3}$, and a "clean" atmosphere free of ice nuclei. Other factors include cloud microphysics effects such as ice scavenging, water vapor deposition, and ice particle melting.

To account for all of these factors, the Current Icing Potential (CIP) algorithm was developed by [30] and was adopted by the National Weather Service and the Federal Aviation Administration. Unfortunately, this approach is unavailable after the HRRR model analysis data has already been produced. Thus, an explicit scheme for computing estimates of SLW over the MEM 3-D domain from the HRRR data is required.

In [31] and [32], a model-based algorithm is defined for use in forecasting freezing precipitation. Within the algorithm, SLW formation is estimated based on cloud microphysics. The authors define a mixed phase scheme to estimate the fraction of liquid to solid water. In [33], another model for SLW formation includes vertical wind to account for updraft coalescence of small drops and downdraft scavenging by graupel.

For this research, SLW fields were estimated using the following scheme:

- Create regions of SLW from addition of cloud liquid water and rain drop mixing ratio amounts

- Constrain SLW to those regions with less than $0.25 \mathrm{~g} / \mathrm{m}^{3}$ liquid water content

- Constrain SLW to those regions where the ambient temperature ranges from $0^{\circ} \mathrm{C}$ to $-20^{\circ} \mathrm{C}$

- Assume HRRR graupel has not scavenged all SLW in regions of down draft winds.

Based on this scheme, SLW fields were estimated from the HRRR data. A sample image is shown in Figure 7 for the entire MEM domain at altitude 11780 feet. 


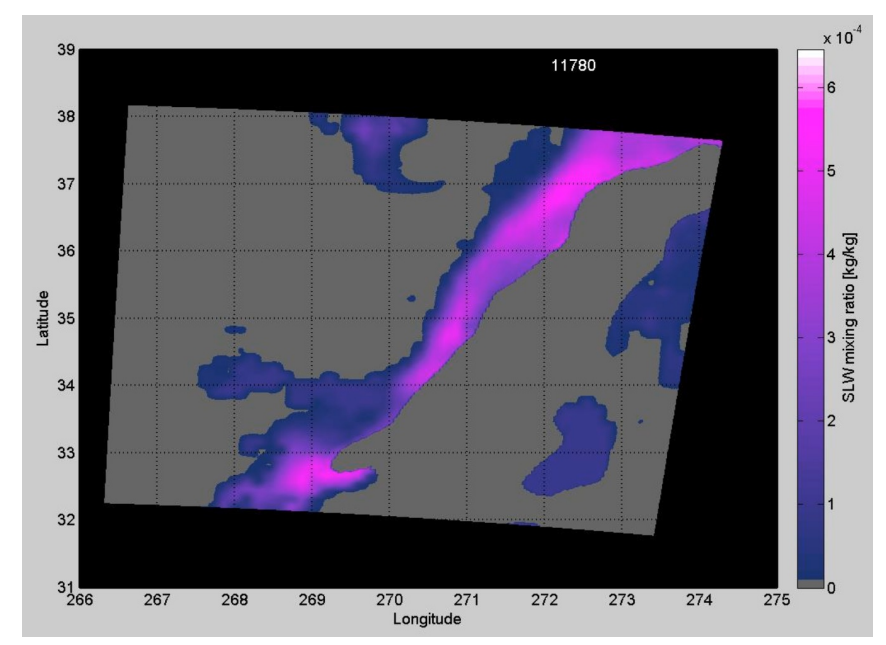

Figure 7: Sample of Supercooled Liquid Water

The RFD B757 dynamic model supports the effect of wing icing for an anti-ice failure mode. In particular, symmetric and asymmetric icing on the wings, and icing on the horizontal tail are supported. A non-dimensional gain, $I_{g}$, is 0.0 for a no ice condition ranging to 1.0 for full ice accretion. This gain value designates the icing severity and was derived from the HRRR based SLW data using a linear equation similiar to that used for the turbulence case. Namely,

$$
I_{g}=\eta_{1}[S L W]+\eta_{2}
$$

where [SLW] is the supercooled liquid water mixing ratio and linear constants $\eta_{1}$ and $\eta_{2}$ determined empirically to achieve the desired aircraft performance degradation.

\section{Data Linked Weather Information}

One key NextGen concept involves the data link of weather information from a ground-based infrastructure or other aircraft. To help fulfil this concept, RTCA SC-206 was established. SC-206 has produced several documents on AIS and MET data link services relevant to this research. The services and assumptions about the environment in which they will operate are described in [8]. The intent is to provide information for pilot decision support for flight efficiency and hazard avoidance. In [9], safety and performance requirements are defined for data link delivery of AIS and MET information. Another document entitled "Concept of Use (ConUse) for Aeronautical Information Services (AIS) and Meteorological (MET) Data Link Services," has been finalized and is scheduled for publication by RTCA by October 2012. System concepts and user applications for using data link for communicating AIS and MET information to and from aircraft are described in this document. The ConUse document covers several types of data linked AIS and MET information pertinent to this research, including: icing, tur- bulence, airport (e.g., runway closure) and airspace (e.g., Temporary Flight Restriction) updates.

For this research, several weather data link products are derived from the HRRR numerical weather data for text and/or graphical display in the RFD. All of these products are consistent with the services envisaged by SC-206, and most are described in the Federal Aviation Administration (FAA) Advisory Circular AC 00-45G. These include:

METAR - Aviation Routine Weather Report - METARs are text reports of surface meteorological data. They include airport identifier, time of observation, wind, visibility, runway visual range, present weather phenomena, sky conditions, temperature, dew point, and altimeter setting.

SPECI - Non-Routine Aviation Weather Report - SPECIs are non-routine, unscheduled text reports in METAR format.

TAF - Terminal Aerodrome Forecasts - TAFs are concise text forecasts for a specified time period within $5 \mathrm{mi}$ of the airport.

NEXRAD reflectivity - NEXRAD graphical images show precipitation information derived from ground Doppler radar sites.

PIREP - Pilot Reports - PIREPs are text or graphical reports of pilot observations.

AIRMET - Airmens Meteorological Conditions - AIRMETs are concise text or graphical advisories of expected en route weather phenomena.

SIGMET - Significant Meteorological Conditions - SIGMETs are text or graphical advisories of potentially hazardous en route phenomena such as severe turbulence or icing affecting a large area or operational safety. Convective SIGMETs are text or graphical advisories issued for thunderstorms and related phenomena. They do not refer to turbulence, icing, or lowlevel wind shear.

Winds and Temperatures Aloft - Winds and Temperatures Aloft are text or graphical forecasts of wind direction and wind speed and temperatures at specified times, altitudes, and locations.

ATIS - Automatic Terminal Information Service - ATIS is a continuous broadcast of recorded information near airports. These broadcasts contain weather, runway and taxiway information, and important NOTAMs. The provision of ATIS over data link is known as Digital ATIS or D-ATIS.

The text form of these products uses an archaic encoding defined to reduce bandwidth requirements on the data link. For example, a SIGMET message encoded as: 
DFWP WS 051700

SIGMET ROMEO 2 VALID UNTIL 052100

AL AR LA MS TN

FROM BNA TO BHM TO BTR TO MLU TO LIT TO BNA

SVR TURB BLW 090 XPCD DUE TO STG NWLY FLOW

BHND CDFNT. CONDS CONTG BYD $2100 \mathrm{Z}$.

must be tranlated by the pilot to:

A SIGMET was issued on the 5th day of the month at 1700 UTC for the Dallas / Fort Worth area forecast region. This is the second SIGMET of the ROMEO series and is valid until the 5th day of the month at 2100 UTC. The affected states are Alabama, Arkansas, Louisiana, Mississippi, and Tennessee. The phenomenon is within a polygon bounded by Nashville; Birmingham; Baton Rouge; Monroe, LA; Little Rock; and Nashville. Severe turbulence below 9,000 feet is expected due to strong northwesterly flow behind a cold front. Conditions will continue beyond the forecast end time of 2100 UTC.

One goal of this research is to enable evaluation of new, more intuitive display formats for pilots. These would include plain language text as well as graphics. The first experiments with these weather products, as described in [11], are part of the HIM/IAN concept.

\section{Flight Deck Displays}

As standard equipment in commercial aircraft, weather radar displays are included in many flight simulators. Further, convection, cloud, rain, and other weather phenomena are modeled by these same simulators for projection as appropriate "out-the-window" scenes. An example of such developments was given in [34]. However, this state-of-the-practice does not derive weather conditions from detailed models of actual conditions occurring in the past, such as the HRRR models. Rather, a designer specified the type of weather conditions (e.g. ceiling, visibility, rain rate) or the range of weather conditions, and the simulator developer designed the system to provide them. Typically, there was little or no connection in the flight simulator between weather in the outthe-window scene, weather shown on flight deck displays, and actual weather conditions.

As a step in this direction, [3] described a Next Generation Integrated Surveillance System as part of a program called FLYSAFE. The WIMS was a sub-system that utilized a ground-based weather processor architecture to convert gridded data to GML data objects to support eventual display. Also, [35] described how WIMS can process convection, icing, turbulence, and wake vortex data as part of the overall FLYSAFE system requirements. There has also been signifi- cant prior research on alternate weather information displays in the flight deck [36] [37] [38] [39] and [40].

For the planned research using the RFD, it is required to use NOAA's HRRR models of actual weather conditions as a common basis for multiple flight deck display functions that involve weather. These functions may provide information to as many as three display devices (per pilot) during experiments. The devices include the primary flight display (PFD), navigation display (ND), and electronic flight bag (EFB).

The initial human-in-the-loop (HITL) experiment that will make use of the new weather simulation capability evaluates two alternate display concepts as well as the standard weather radar display [41]. Of the alternate display concepts under test, the first strictly involves the EFB and will provide a means for pilots to receive and review weather information that is provided via data link during flights. For this display function, pilots will receive text-based reports (e.g. as described previously for TAFs, METARs, and SIGMETs). They will also be able to see graphical geo-referenced depictions of these same reports in many cases. These graphical display concepts for the EFB will be similar in function to aviation weather information currently available in-flight via satellite (e.g. WSI and WxWorx) and via ADS-B (e.g. WingX and Stratus). In addition, the EFB will provide Notices to Airmen (NOTAMs) that may occur during flight (text and graphical). The key here is that the information provided and displayed must be commensurate with the HRRR weather model used as a basis for all the other weather-related aspects of the simulation.

The second and more complex, display concept to be studied is the HIM/IAN system's conflict probing function [11] [42] and [10]. This concept provides the crew with a display of hazard regions ahead, along, and near the projected flight path. These regions are shown on both the PFD and the ND. These hazard regions also indicate the locations of conflict-free paths, and as such, allow for the generation of alternate trajectories should the current flight path be projected to enter one of the hazard regions. The key point of this function is that the hazard regions are generated based upon "all" possible external hazards. This includes primarily: traffic, terrain, airspace restrictions, and weather.

For this display function to perform, a representation of where the weather is, and where it is moving, is required. These hazardous regions or objects are described as a set of cylinders that enclose the appropriate region of airspace. For the initial set of cylinders, the region incorporates radar reflectivity that exceeds a prescribed threshold. Initially, $40 \mathrm{dBZ}$ was selected (corresponding to the color "red" on the standard weather radar display. The HRRR-based radar reflectivity data was used to define the set of hazardous weather objects. Shown in Figure 8 is a sample of a $3 \mathrm{D}$ region with $40 \mathrm{dBZ}$ or greater radar reflectivity. 


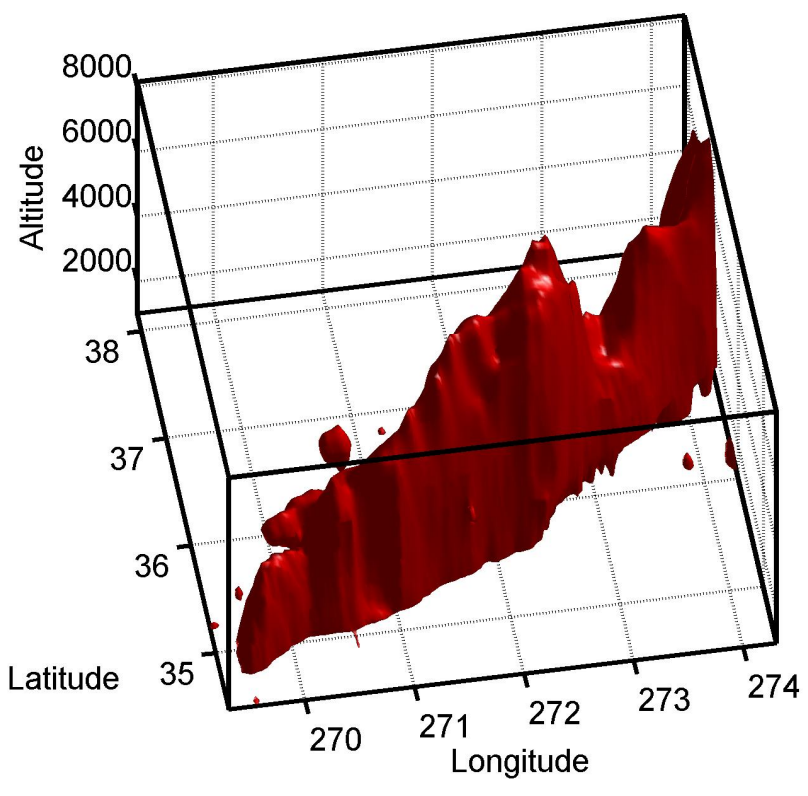

Figure 8: Sample of 3D Radar Reflectivity

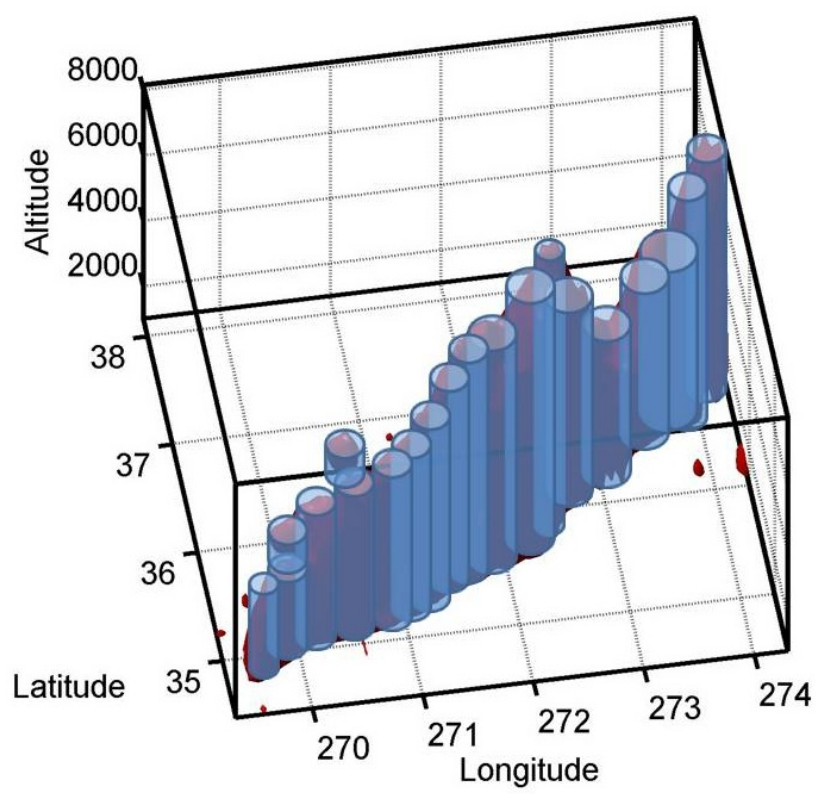

Figure 9: Sample of 3D Weather Cells

This irregularly-shaped weather hazard region can be approximated by a set of cylinders. For example, the hazardous regions shown in Figure 8 are approximated by cylinders as shown in Figure 9. The cylinders can have any size, but must conform to a cylindrical shape. These cylinders are used by the IAN/HIM system to enable display (on the PFD and ND) and to allow for conflict probing. Figure 10 shows the top view for an example of how a set of the cylindrical shapes

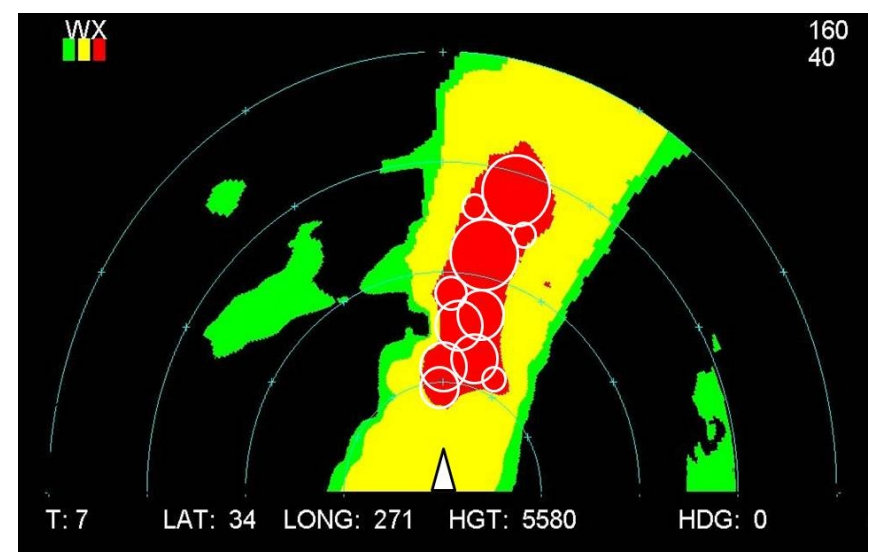

Figure 10: View of Weather Cylinder Shapes for Sample Radar Reflectivity of Figure 5

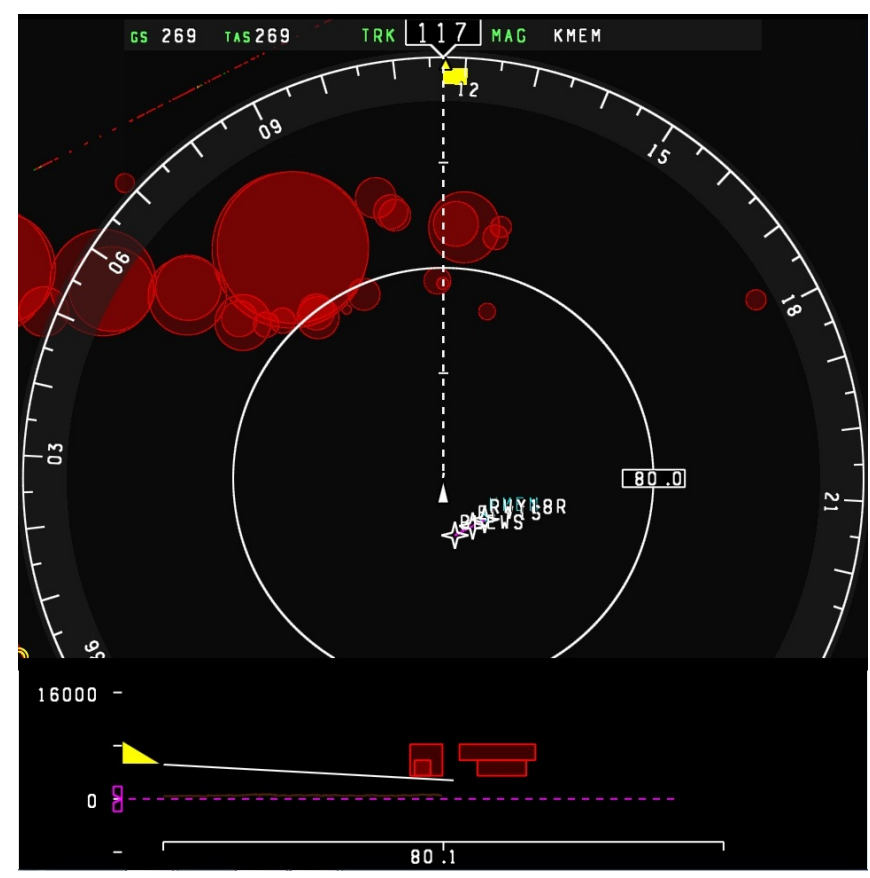

Figure 11: Prototype Navigation Display of Weather Hazards Cylinders

can be used to approximate the location and size of the hazard region previously shown in Figure 5 . The vertical extent of each cylinder is corresponds to the HRRR radar reflectivity over the range of altitudes. In a similar manner, HRRR based hazardous weather objects my be created for turbulence and icing regions.

Figure 11 illustrates a preliminary concept for display of the weather hazard cylinders on the ND. In the figure, the bottom portion is known as the Vertical Situation Display. The yellow triangle represents the ownship with a white line depicting the projected flight path. Only those weather hazards directly along the flight path are selected by the HIM 
for display. The top portion of the figure is the corresponding horizontal situation display.

The final versions of all display concepts to be tested and the results of this testing using the new weather simulation capability described herein, will be published in subsequent research publications.

\section{Conclusion}

Piloted simulation experiments are being conducted in the NASA Langley RFD Simulator for the development of advanced flight deck systems to support safe and efficient operations in the presence of potentially hazardous weather conditions. For potential use in the NextGen, research prototypes of hazard sensors, information processing systems, and display concepts are being evaluated. In order to provide a realistic weather environment for the RFD simulation experiments, HRRR model data was employed to drive three capabilities: (1) the weather conditions in which the simulator operates (2) simulation of the airborne weather radar system (3) data linked weather information.

Taumi Daniels, Philip Schaffner, Emory Evans Robert Neece and Steven Young

August 24, 2012

\section{Acknowledgments}

The authors would like to thank their colleagues in the Vehicle Systems Safety Technologies Project at NASA Langley Research Center. The authors would also like to express their appreciation to Dr. Stan Benjamin, Dr. John Brown, Dr. William Moninger, Eric James, Dr. Tom Schlatter and John Schneider of NOAA Earth Systems Research Laboratory for their time, effort, expertise, and above all - the weather data. In addition, the software development and testing efforts of Pengfei "Phil" Duan and Dr. Maarten Uijt de Haag at Ohio University were significant and vital contributions to this project.

\section{References}

[1] Heesbeen, B. W., Ruigrok, R. C., and Hoekstra, J. M., "GRACE a versatile simulator architecture making simulation of multiple complex aircraft simple," Proceedings of the AIAA Modeling and Simulation Technologies Conference and Exhibit, Keystone, CO, August 2006.

[2] Pradier-Vabre, S., Forster, C., Heesbeen, W., Pagé, C., Sénési, S., Tafferner, A., Bernard-Bouissières, I., Caumont, O., Drouin, A., Ducrocq, V., Guillou, Y., and Josse, P., "Description of convective-scale numerical weather simulation use in a flight simulator within the
Flysafe project," Meteorology and Atmospheric Physics, Vol. 103, 2009, pp. 127-136.

[3] Mirza, A. K., Pagé, C., and Geindre, S., "FLYSAFE An Approach to Safety using GML/XML objects to define hazardous volumes of aviation space," 13th Conference on Aviation, Range, and Aerospace Meteorology, AMS, New Orleans, 20-24 January 2008.

[4] Doehler, H.-U. and Peinecke, N., "An evaluation test bed for enhanced vision," Enhanced and Synthetic Vision 2010, edited by J. J. Guell and K. L. Bernier, Vol. 7689, SPIE, 2010, p. 768907.

[5] Alexander, C. R., Weygandt, S. S., Smirnova, T. G., Benjamin, S., Hofmann, P., James, E. P., and Koch, D. A., "High resolution rapid refresh (HRRR): Recent enhancements and evaluation during the 2010 convective season," 25th Conference on Severe Local Storms, No. 9.2, AMS, Denver, CO, 11-14 October 2010.

[6] Benjamin, S. G., Dévényi, D., Weygandt, S. S., Brundage, K. J., Brown, J. M., Grell, G. A., Kim, D., E.Schwartz, B., Smirnova, T. G., Smith, T. L., and Manikin, G. S., "An Hourly Assimilation - Forecast Cycle: The RUC," Monthly Weather Review, Vol. 132, No. 2, February 2004, pp. 495-518.

[7] Benjamin, S. G., Grell, G. A., Brown, J. M., Smirnova, T. G., and Bleck, R., "Mesoscale Weather Prediction with the RUC Hybrid Isentropic - Terrain - Following Coordinate Model," Monthly Weather Review, Vol. 132, No. 2, February 2004, pp. 473-494.

[8] RTCA Special Committee 206, “DO-308, Operational Services and Environment Definition (OSED) for Aeronautical Informational Services (AIS) and Meteorological (MET) Data Link Services," [Website] Retrieved from http://www.rtca.org/doclist.asp, August 2012.

[9] RTCA Special Committee 206, “DO-324, Safety and Performance Requirements (SPR) for Aeronautical Information Services (AIS) and Meteorological (MET) Data Link Services," [Website] Retrieved from http://www.rtca.org/doclist.asp, August 2012.

[10] Tadema, J., Theunissen, E., Rademaker, R., and Uijt de Haag, M., "Evaluating the Impact of Sensor Data Uncertainty and Maneuver Uncertainty in a Conflict Probe," Proceedings of the 29th Digital Avionics Systems Conference, Salt Lake City, UT., 2010, pp. 4C3.14C3.16.

[11] Duan, P. and Uijt de Haag, M., "A Simulation Environment for Evaluation of Integrated Alerting and Notification (IAN) Concepts," Proceedings of the 31th Digital 
Avionics Systems Conference, Williamsburg, VA, October 2012.

[12] Smith, R. M., "A Description of the Cockpit Motion Facility and the Research Flight Deck Simulator," AIAA 20004174, Modeling and Simulation Technologies Conference and Exhibit, No. AIAA-2000-4174, 2000, pp. 14-17.

[13] FlightStats, Inc., "Airport Delays," [Website] Retrieved from http://www.flightstats.com/go/Airport/delays.do, November 2011.

[14] Morrison, H., Thompson, G., and Tatarskii, V., "Impact of Cloud Microphysics on the Development of Trailing Stratiform Precipitation in a Simulated Squall Line: Comparison of One- and Two-Moment Schemes," Monthly Weather Review., Vol. 137, No. 3, March 2009, pp. 991-1007.

[15] Grell, G. A. and Dévényi, D., “A generalized approach to parameterizing convection combining ensemble and data assimilation techniques," Geophysical Research Letters, Vol. 29, No. 14, July 2002, pp. 1693-1697.

[16] Mahapatra, P., Aviation Weather Surveillance Systems: Advanced Radar and Surface Sensors for Flight Safety and Air Traffic Management, No. 8 in IEE Radar, Sonar, Navigation and Avionics, American Institute of Aeronautics and Astronautics, 1999.

[17] Wexler, R. and Atlas, D., "Radar Reflectivity and Attenuation of Rain," Journal of Applied Meteorology, Vol. 2, No. 2, April 1963, pp. 276-280.

[18] Steiner, M., Smith, J. A., and Uijlenhoet, R., “A Microphysical Interpretation of Radar Reflectivity and Rain Rate Relationships," Journal of Atmospheric Science, Vol. 61, No. 10, May 2004, pp. 1114-1131.

[19] Paluch, I. R., Knight, C. A., and Miller, L. J., "Cloud Liquid Water and Radar Reflectivity of Nonprecipitating Cumulus Clouds," Journal of Atmospheric Science, Vol. 53, No. 11, June 1996, pp. 1587-1603.

[20] Sekhon, R. and Srivastava, R., "Snow Size Spectra and Radar Reflectivity," Journal of Atmospheric Science, Vol. 27, No. 2, March 1970, pp. 299-307.

[21] Löffler-Mang, M. and Blahak, U., "Estimation of the Equivalent Radar Reflectivity Factor from Measured Snow Size Spectra," Journal of Applied Meteorology, Vol. 40, No. 4, April 2001, pp. 843-849.

[22] Smith, P., "Equivalent Radar Reflectivity Factors for Snow and Ice Particles," Journal of Climate and Applied Meteorology, Vol. 23, No. 8, Aug. 1984, pp. 1258-1260.
[23] Molthan, A. L. and A.Petersen, W., "Incorporating Ice Crystal Scattering Databases in the Simulation of Millimeter-Wavelength Radar Reflectivity," Journal of Atmospheric and Oceanic Technology, Vol. 28, No. 3, Nov. 2010, pp. 337-351.

[24] Matrosov, S. Y., Campbell, C., Kingsmill, D., and Sukovich, E., "Assessing Snowfall Rates from X-Band Radar Reflectivity Measurements," Journal of Atmospheric and Oceanic Technology, Vol. 26, No. 11, Nov. 2009, pp. 2324-2339.

[25] Stoelinga, M., "Description of the Simulated Equivalent Reflectivity Factor Calculation in RIP," [Website] Retrieved from http://www.atmos.washington.edu/ stoeling/.

[26] Crum, T. D. and Alberty, R. L., "The WSR-88D and the WSR-88D Operational Support Facility," Bulletin of American Meteorological Society, Vol. 74, No. 9, Sept. 1993, pp. 1669-1687.

[27] Kelly, W., Kronfeld, K., and Rand, T., "Cockpit integration of uplinked weather radar imagery," Proceedings of the 19th Digital Avionics Systems Conference, Vol. 1, 2000, pp. 3D4/1 -3D4/6.

[28] Lane, T. P., Sharman, R. D., Trier, S. B., Fovell, R. G., and Williams, J. K., "Recent Advances in the Understanding of Near-Cloud Turbulence," Bulletin of American Meteorological Society, Vol. 93, No. 4, October 2011, pp. 499-515.

[29] Wang, S.-T. and Frost, W., "Atmospheric Turbulence Simulation Techniques With Application to Flight Analysis," Tech. Rep. CR-3309, National Aeronautics and Space Administration, September 1980.

[30] Bernstein, B., McDonough, F., Politovich, M., Brown, B., Ratvasky, T., Miller, D., Wolff, C., and Cunning, G., "Current Icing Potential: Algorithm Description and Comparison with Aircraft Observations," Journal of Applied Meteorology, Vol. 44, No. 7, July 2005, pp. 969-986.

[31] Tremblay, A. and Glazer, A., "An Improved Modeling Scheme for Freezing Precipitation Forecasts," Monthly Weather Review, Vol. 128, No. 5, May 2000, pp. 12891308.

[32] Vaillancourt, P. A., Tremblay, A., Cober, S. G., and Isaac, G. A., "Comparison of Aircraft Observations with Mixed-Phase Cloud Simulations," Monthly Weather Review, Vol. 131, No. 4, April 2003, pp. 656-671. 
[33] Khain, A. P., Rosenfeld, D., and Pokrovsky, A., "Simulating convective clouds with sustained supercooled liquid water down to $-37.5^{\circ} \mathrm{C}$ using a spectral microphysics model," Geophysical Research Letters, Vol. 28, No. 20, 2001, pp. 3887-3890.

[34] Sullivan, B. T. and Soukup, P. A., "The NASA $747-$ 400 flight simulator - A national resource for aviation safety research," AIAA Flight Simulation Technologies Conference, No. AIAA-1996-3517, AIAA, San Diego, CA, 29-31 July 1996, pp. 374-384.

[35] Gerz, T., Tafferner, A., Rosczyk, S., Mirza, A., Turp, D., and Bot, C. L., "Improved Weather Information for Cockpit and Tower," 25th International Congress of the Aernautical Sciences, No. ICAS 2006-9.5.2, Hamburg, Germany, September 2006.

[36] Bliss, J., Fallon, C., Bustamante, E., Bailey, III, W., and Anderson, B., "Reactions of Air Transport Flight Crews to Displays of Weather During Simulated Flight," Tech. Rep. ODURF-130971, NASA Langley Research Center, 2005.

[37] Dao, A.-Q. V., Brandt, S. L., Bacon, P., Kraut, J., Nguyen, J., Minakata, K., Raza, H., Rozovski, D., and Johnson, W., "Conflict Resolution Automation and Pilot Situation Awareness," Tech. Rep. ARC-E-DAATN1371, NASA Ames Research Center, 2010.

[38] Comerford, D. A., "Recommendations for a Cockpit Display that Integrates Weather Information with Traffic Information,” Tech. Rep. NASA/TM-2004-212830, NASA Ames Research Center, 2004.

[39] Novacek, P., Burgess, M., Heck, M., Stokes, A., and Stough, III, P., "The Effect of Ownship Information and NexRad Resolution on Pilot Decision Making in the Use of a Cockpit Weather Information Display," Tech. Rep. NASA/CR-2001-210845, NASA Langley Research Center, 2001.

[40] Yuchnovicz, D., Novacek, P., Burgess, M., Heck, M., and Stokes, A., "Use of a Data-Linked Weather Information Display and Effects on Pilot Navigation Decision Making in a Piloted Simulation Study," Tech. Rep. NASA/CR-2001-211047, NASA Langley Research Center, 2001.

[41] Airlines Electronic Engineering Committee, "Airborne Weather Radar," Tech. rep., Aeronautical Radio, Inc., 1991.

[42] Tadema, J., Unmanned Aircraft Systems HMI \& Automation Tackling Control, Integrity and Integration Issues, Ph.D. thesis, Delft University of Technology, 2011. 31th Digital Avionics Systems Conference

October 16-20, 2012 